\title{
Comparative Evaluation of Apical Debris Extrusion with Single File Systems Used under Different Kinematics
}

\author{
${ }_{1}^{1}$ Parag Srivastav, ${ }^{2}$ Ashwini Prasad, ${ }^{3}$ Deepak Raisingani, ${ }^{4}$ Abhilasha Dixit, ${ }^{5}$ Aseem Jain, ${ }^{6}$ Akshay Arya
}

\begin{abstract}
Aim: The study was designed to evaluate and compare the amount of apical debris extruded from the root canals using two different file systems Wave One (Dentsply Maillefer, Ballaigues, Switzerland) and One Shape ${ }^{\circledR}$ (Micro-Mega, France) when they were used under different kinematics, i.e., continuous and reciprocating motions.
\end{abstract}

Materials and methods: A total of fourty single-rooted human teeth with a single root canal and apical foramen were selected and shaped with wave one and one shape file system. The debris was collected in an empty vial. The dry weight of extruded debris was weighed in an electronic balance by subtracting the pre-instrumented weight from post instrumented weight.

Statistical analysis: The mean weights of extruded debris were statistically analyzed using a paired t-test.

Result: The use of these file systems (Wave One and One Shape ${ }^{\circledR}$ ) in reciprocating motion resulted in more debris extrusion then when the continuous motion was used. The mean debris extruded by both one shape and wave one file systems were equal.

Conclusion: Use of reciprocating motion file system causes a greater extrusion of apical debris out of apical foramen.

Keywords: Continous motion, Debris extrusion, Kinematics, Reciprocating motion, Root canal preparation.

How to cite this article: Srivastav $P$, Prasad $A$, Raisingani $D$, Dixit A, Jain A, Arya A. Comparative Evaluation of Apical Debris Extrusion with Single File Systems Used under Different Kinematics. J Oper Dent Endod 2018;3(2):79-82

Source of support: Nil

Conflict of interest: None

\section{INTRODUCTION}

Pulp tissue, microorganisms, dentin chips, and irrigants may be extruded into periapical tissues. This causes pain, inflammation, delayed healing and the patient reports with an endodontic flare up. The most common reason behind this is an apical extrusion of dentinal debris, pulp

\footnotetext{
${ }^{1,4-6}$ Postgraduate Student, ${ }^{2}$ Reader, ${ }^{3}$ Professor and Head

${ }^{1-6}$ Department of Conservative Dentistry and Endodontics, Mahatama Gandhi Dental College and Hospital, Jaipur, Rajasthan, India

Corresponding Author: Abhilasha Dixit, Postgraduate Student, Department of Conservative Dentistry and Endodontics, Mahatama Gandhi Dental College and Hospital, Jaipur, Rajasthan, India, e-mail: abhilasha.dxt@gmail.com
}

tissue, irrigants and the various microorganisms present in the root canals. Confining the preparation to areas above the apical terminus can decrease the extrusion of debris into the periradicular tissues. ${ }^{1}$ Literature suggests that all current instrumentation techniques result in extrusion of intracanal content into the periradicular tissues, even when the area of preparation does not extend to the apical terminus, but the amount of extruded debris differs between instruments and file designs. ${ }^{1}$

Various rotary and reciprocating file systems are getting introduced in the market having different kinematics and file designs. The One Shape ${ }^{\circledR}$ (Micro-Mega, Besancon, France) is a single file, full-sequence rotary National Institution for Transforming India (NiTi) instrument that is designed to prepare the entire root canal with only one instrument. It is made of traditional NiTi alloy and works in a continuous, clockwise, rotational motion, ${ }^{1}$ while the Wave One (Dentsply Maillefer, Ballaigues, Switzerland) system is made of a special heat-treated NiTi alloy called M-wire, which is claimed to increase flexibility and resistance to cyclic fatigue. ${ }^{2,3}$ Preprogrammed reciprocation motions that are specific to their file designs are used by this file system.

Studies have been conducted to evaluate the amount of debris extruded using various instruments and instrumentation techniques so that we can find a file system which extrudes the minimum amount of debris and thus eventually reduce the post instrumentation flare-ups.

There has been no study conducted which compares these two file systems. Thus, the purpose of the current study is to analyze and evaluate the apical extrusion of debris using one shape and wave one under different kinematic settings, i.e., continuous and reciprocating motion.

\section{MATERIALS AND METHODS}

This study was conducted after receiving an ethical clearance from the research committee in the Department of Conservative Dentistry and Endodontics. Total fourty extracted maxillary central incisors which were non-carious had completely formed apices and had a single root, and the single canal was included in the study. Fractured, restored, teeth with developmental defects and internal/external resorption were excluded. Four groups were made, and ten teeth were kept in each group. Specimens were stored in distilled water until use. All the specimens were decoronated off the 
cementoenamel junction (CEJ)level using a round diamond disc and straight handpiece to obtain $14+/-1 \mathrm{~mm}$ root length sections (Fig. 1). The working length was determined with number $10 \mathrm{~K}$ file up to root canal terminus and subtracting 1 $\mathrm{mm}$ from it and confirmed radiographically. The size of the minor foramen was controlled using the number $20 \mathrm{~K}$ file.

An endodontic motor with both continuous and reciprocating motion settings (X-smart plus, Dentsply) was used with 6:1 gear reduction handpiece. One empty vial was taken per tooth. A hole was made into the stopper cap of the vial, and the tooth was snugly fit into it. A 24 gauge needle was inserted into the rubber stopper to equalize the air pressure and sealed with cyanoacrylate resin[ (Fig. 2). Before placing the stopper on the vial, the empty vial was weighed three times on the high precision weighing balance (Sansui SSP 300) which is accurate up to $0.001 \mathrm{gm}$. The mean of the three weights was taken to be the weight of the empty vial. The stopper cap was placed back into the vial.

The canal was filled with $0.5 \mathrm{~mL}$ of distilled water, and the first group was instrumented up to the working length with One Shape in continuous motion (350 rpm/2.5 $\mathrm{N} / \mathrm{Cm}^{2}$ ), second group with One Shape in reciprocating motion (pre-programmed setting), third group with Wave One in continuous motion (350 rpm/2.5N/ $\mathrm{Cm}^{2}$ ) and the fourth group with Wave One in reciprocating motion (preprogrammed setting). No other irrigant, other than distilled water was used for irrigation. Once the instrumentation was complete, the stopper cap was removed, and the apex of the tooth was washed off with $1 \mathrm{~mL}$ of distilled water into the vial. The vials were stored with silica desiccant gel overnight

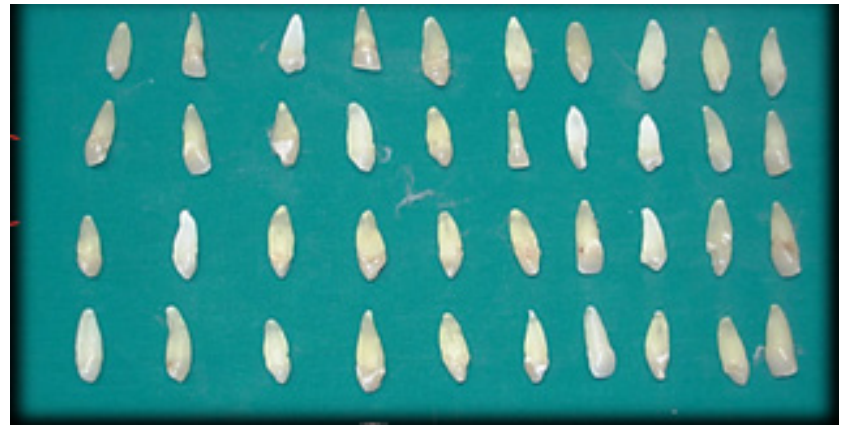

Fig. 1: Decoronated sections to absorb any excess moisture. To evaluate the amount of apical debris extruded, out of the root canal space, a modified method as described by Moyers and Montgomery was used. The vials were again weighed over the balance, three times each to get the mean weight of each vial post instrumentation. The amount of apical debris extruded was calculated by subtracting the empty weight of the vial from the post instrumentation weight.

\section{RESULTS}

Mean debris extruded by both the systems (One Shape ${ }^{\circledR}$ file system and Wave One file system) was equal that is $(0.0065 \pm 0.001)$ (Table 1$)$.

Mean debris extruded was lesser in study samples shaped with the continuous rotary motion of file with $0.0045 \pm 0.001$ weight in grams than the reciprocating rotary motion of with mean debris extruded $0.0076 \pm$ 0.002 weight in grams (Table 2).

On applying paired T-test to compare mean debris weight in grams to the One Shape ${ }^{\circledR}$ and Wave One file systems used states that there is a high statistical difference $\left(p \leq 0.000^{* * *}\right)$ between One Shape ${ }^{\circledR}$ and Wave One file systems used regarding mean debris extruded (Table 3 ).

On applying paired T-test to compare mean debris weight in grams to the reciprocating and continuous rotary motion of file states that there is a statistical

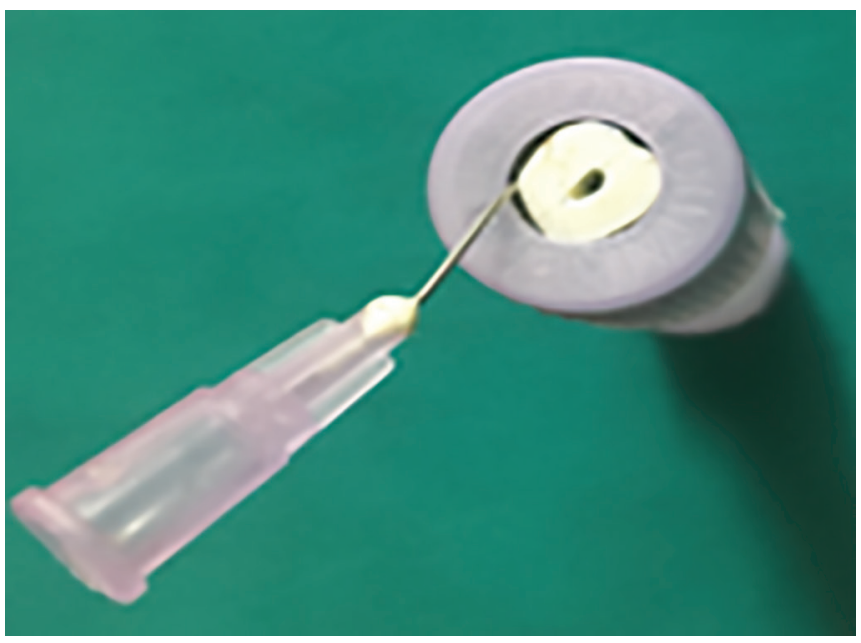

Fig. 2: Tooth mounting assembly

Table 1: Mean debris extruded by One Shape file system and Wave One file system

\section{File system}

One Shape File System

Mean \pm standard deviation

$0.0065 \pm 0.001$ weight in grams
Wave one file system

Mean \pm standard deviation

$0.0065 \pm 0.001$ weight in grams

Table 2: Mean debris extruded by reciprocating and continous rotary motion of file

\begin{tabular}{ll}
\hline File motion & \\
\hline Reciprocation file motion & Continous file motion \\
Mean \pm standard deviation & Mean \pm standard deviation \\
$0.0076 \pm 0.002$ weight in grams & $0.0045 \pm 0.002$ weight in grams \\
\hline
\end{tabular}


Table 3: Comparison of mean debris weight in grams to the to the reciprocating and continuous rotary motion of file

\begin{tabular}{lll}
\hline Group compared & $p$-value & Significance \\
\hline One Shape file system and & $0.000^{\star * *}$ & Highly significant difference \\
Wave One file system used & & \\
\hline
\end{tabular}

$\mathrm{p} \leq 0.000 * * *, \mathrm{p} \leq 0.001 * *, \mathrm{p} \leq 0.05 *$

Table 4: Comparison of mean debris weight in grams to the One Shape file system and Wave One system used

\begin{tabular}{lll}
\hline Group compared & $p$-value & Significance \\
\hline $\begin{array}{l}\text { Reciprocating and continuous } \\
\text { rotary motion of file }\end{array}$ & $0.02^{*}$ & Normally significant difference \\
\hline
\end{tabular}

$\mathrm{p} \leq 0.000 * * *, \mathrm{p} \leq 0.001 * *, \mathrm{p} \leq 0.05 *$

difference $\left(\mathrm{p} \leq 0.05^{*}\right)$ between reciprocating and continuous rotary motion of file used regarding mean debris extruded ( Table 4).

\section{DISCUSSION}

Instrumentation is an indispensable criterion to obtain thorough shaping and cleaning of the root canals. We cannot prevent the debris extrusion, but we certainly can use file systems which can cause less of these complications thus reducing the endodontic flare-ups. In the present study, we attempted to discover, that to what extent the kinematics of a file system matters.

The instrumentation in endodontics began with hand files. But, studies have shown that manual instrumentation produced significantly more debris than the rotary national institution for transforming India (NiTi) techniques and the balanced-force technique. ${ }^{4}$ It was observed that rotation during instrumentation, with both the rotary and balanced-force techniques, tend to pull dentinal debris into the flutes of the file and direct it toward the coronal aspect of the canal. ${ }^{4}$ In case of engine-driven instruments, early flaring of the coronal part of the preparation may improve instrument control during the preparation of the apical third of the canal. ${ }^{5}$ Thus, engine driven instruments were considered better overhand instruments regarding debris extrusion. But, we needed a study which compares the engine driven instruments, used under different kinematics to find the one, causing least extrusion.

The present study evaluated the amount of apical debris extruded in One Shape ${ }^{\circledR}$ and Wave One file systems, in both rotary and reciprocating motions. The apically extruded debris was collected based on the widely accepted experimental setup of Myers and Montgomery (Fig. 3). ${ }^{6}$

This is an in vitro study, thus cannot mimic the exact conditions present in the vital periapical tissues, but the condition permits the comparison of file systems. Distilled water was used as irrigant to prevent any decrease in the weight of debris because of dissolution by sodium hypochlorite.

Paired T-test stated that there was a statistical difference $\left(\mathrm{p} \leq 0.05^{*}\right)$ between reciprocating and continu-

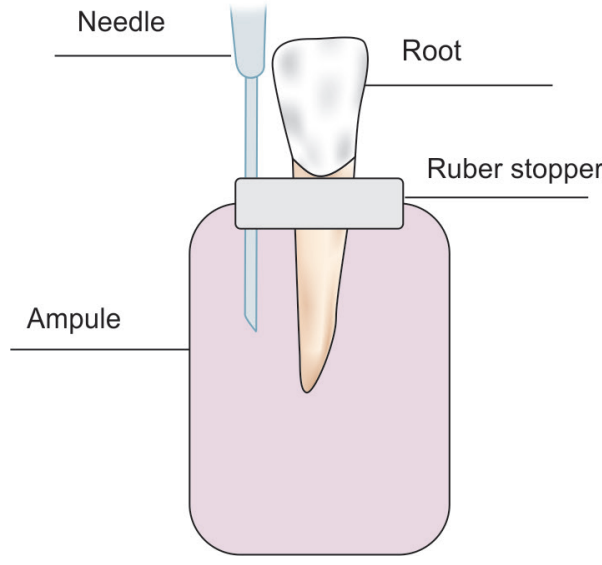

Fig. 3: The experimental setup of Myers and Montgomery

ous rotary motion of file used regarding mean debris extruded.

The differences which were observed may be because of reasons like the cross-sectional design of the instruments and kinematic motion of the files. The triangular or modified triangular cross-section of Wave One produces a lower cutting efficiency and smaller chip space. The smaller chip space limits their ability to allow coronal removal of debris resulting in a piston-like action. ${ }^{7}$ Thus, instrumentation in reciprocal motion may enhance debris transportation toward the apex. While a continuous rotary motion acts like a screw conveyor and improves the coronal transportation of dentin debris. ${ }^{7}$

The results of the present study were similar to the study done where the single-file reciprocating Wave One and Reciproc instruments were compared to fullsequence rotary instrumentation systems (ProTaper universal and Mtwo), the single-file systems caused more debris than the other systems.

Preparing the entire canal with only one single file instead of sequential multifile systems has simplified instrumentation and could be one of the reasons that singlefile rotary systems result in less extrusion of debris. ${ }^{1}$

The expansion of the apical diameter promoted by the instruments may also influence the amount of extruded debris. Precisely, the enlargement may directly correlate with the extent of extrusion. The greater taper at the tip 
of the Wave One may also be a reason for greater debris extrusion as compared to One Shape because of the more preparation of the canal walls. ${ }^{8}$

There are a few limitations of this study. The results obtained cannot be generalized to all the teeth because only teeth with single and completely formed roots having a $<20^{\circ}$ curvature were selected. There is no way by which the periapical tissues can be replicated in an in vitro study. Thus, the results can vary in clinical condition because of the presence of back pressure provided by periapical tissues, and apical extrusion is limited. Moreover, irrigation could be considered one of the primary causes of apical debris extrusion because instrumentation with irrigation produces extrusion, whereas instrumentation without irrigation does not produce any collectible debris. ${ }^{8}$

\section{CONCLUSION}

There are pros and cons of every invention. The reciprocating motion files are indeed proven to be better than the continuous motion files when it comes to cutting efficiency and cleaning ability but, they also have a drawback of apical extrusion of debris which in turn causes inflammatory responses in the periapical area. Thus, when it comes to the question that who would eventually win the race between reciprocating and rotary, the answer is yet dilemmatic.

\section{REFERENCES}

1. Ehsani M, Farhang R, Harandi A, Tavanafar S, Raoof M, Galledar S. Comparison of Apical Extrusion of Debris by Using Single-File, Full-Sequence Rotary and Reciprocating Systems. Journal of Dentistry (Tehran, Iran). 2016;13(6):394-399.

2. Al-Hadlaq S, AlJarbou F, AlThumairy R. Evaluation of Cyclic Flexural Fatigue of M-Wire Nickel-Titanium Rotary Instruments. Journal of Endodontics. 2010;36(2):305-307.

3. Alapati S, Brantley W, Iijima M, Clark W, Kovarik L, Buie C et al. Metallurgical Characterization of a New Nickel-Titanium Wire for Rotary Endodontic Instruments. Journal of Endodontics. 2009;35(11):1589-1593.

4. Surakanti J, Venkata R, Vemisetty H, Dandolu R, Jaya N, Thota S. Comparative evaluation of apically extruded debris during root canal preparation using ProTaper ${ }^{\mathrm{TM}}$, Hyflex ${ }^{\mathrm{TM}}$ and Wave One ${ }^{\mathrm{TM}}$ rotary systems. Journal of Conservative Dentistry. 2014;17(2):129.

5. Madhusudhana K, Mathew VB, Reddy NM. Apical extrusion of debris and irrigants using hand and three rotary instrumentation systems-An in vitrostudy. Contemporary Clinical Dentistry. 2010;1(4):234-236.

6. Myers GL, Montgomery S. A comparison of weights of debris extruded apically by conventional filing and Canal Master techniques. J Endod. 1991;17(6):275-279.

7. Subbiya A, Vivekanandhan P, Mitthra S, Karthick A. Comparison of apical debris extrusion of two rotary systems and one reciprocating system. Journal of Conservative Dentistry. 2016;19(3):245.

8. Nevares G, Xavier F, Gominho L, Cavalcanti F, Cassimiro M, Romeiro K et al. Apical Extrusion of Debris Produced during Continuous Rotating and Reciprocating Motion. The Scientific World Journal. 2015;2015:1-5. 